\title{
ENHANCED LIGHT EMISSION IN NANOSTRUCTURES
}

\author{
J. Kundrotas a , A. Čerškus a , V. Nargelienè a, A. Sužiedèlis a , S. Ašmontas ${ }^{\text {a }}$, J. Gradauskas a, \\ A. Johannessen ${ }^{b}$, and E. Johannessen ${ }^{b}$ \\ a Semiconductor Physics Institute, Center for Physical Sciences and Technology, A. Goštauto 11, LT-01108 Vilnius, \\ Lithuania \\ E-mail:kundrot@pfi.lt \\ ${ }^{\mathrm{b}}$ Vestfold University College, Raveien 197, 3184 Borre, Norway
}

Received 27 October 2011; accepted 1 December 2011

\begin{abstract}
The enhancement of light emissive processes in different quantum nanometric systems is presented in this review. The plasmonic enhanced photoluminescence (fluorescence) of metals and metal nanoparticles, molecules and semiconductor nanostructures, as well as surface-enhanced Raman scattering is initially considered. The enhancement of excitonic photoluminescence intensity in semiconductor confined systems such as quantum wells, quantum wires and quantum dots, and microcavities are then discussed. Finally, the experimental results of the enhanced exciton photoluminescence from GaAs homojunctions, $\delta$-doped GaAs structures, GaAs/AlGaAs selectively doped and AlInN/GaN heterostuctures is presented. These results can be applied to enhance the emission of light-emitting diodes, as well as to increase the efficiency of solar cells.
\end{abstract}

Keywords: plasmonics, photoluminescence, fluorescence, SERS, MEF, quantum wells, heterostructures

PACS: 73.20.Mf, 73.21.-b, 78.55.-m, 78.30.-j, 78.67.Bf

\section{Bulk and surface plasmons in metals}

A few metals and their nanoparticles offer resonances of their carrier transitions that fall near or in the visible region of the electromagnetic spectrum. The best material candidates are alkali and noble metals. Noble metals have the additional advantage of being chemically inert, i. e. not very reactive, and hence do not require vacuum in order to perform an experiment. The two most common metals are silver $(\mathrm{Ag})$ and gold $(\mathrm{Au})$, which are widely used in various nanophotonics applications [1].

Noble metal nanoparticles have been used to change the colours of reflected or transmitted light in both architecture and art over several hundreds of years. The staining of glass windows or ornamental cups are the best known examples [2]. More practical optical applications have been limited to reflectors due to the large free electron densities of metals, in which the electrons are highly delocalized over a large surface space. However, we can decrease the size of the metal surface and confine its electronic motion. The decrease in size of metal nanoparticles gives rise to an intense absorption of light, which is called surface plasmon absorption. This intense absorption induces a strong coupling of the nanoparticles to the electromagnetic radiation of light.

Plasmons consist of coherent oscillations of conduction-band-electrons and are primarily responsible for the optical properties of metals. The Drude plasma frequency for the free electron gas equals $\omega_{\mathrm{p}}=\sqrt{n e^{2} /\left(\varepsilon_{0} m_{\mathrm{e}}\right)}$, where $n$ is the number of electrons per unit volume, $m_{\mathrm{e}}$ is electron mass, $e$ is the electron charge, and $\varepsilon_{0}$ is the electric constant $[3,4]$. The dielectric constant of metals is a complex function of frequency, and the real part changes from 
negative to positive as we go through the plasma frequency and dielectric constant is equal to zero at the plasma frequency. This means that metals will transmit light in the ultraviolet range for frequencies above the plasmon resonance $\left(\omega>\omega_{\mathrm{p}}\right)$, whereas light below the plasmon resonance is fully reflected. The plasmon energy of free electrons for both $\mathrm{Au}$ and $\mathrm{Ag}$ is about $\hbar \omega_{\mathrm{p}} \approx 9 \mathrm{eV}$ [5]. However, due to the contributions of core bound electrons, the plasmon energy shifts to a lower energy level which becomes equal to $\hbar \omega_{\mathrm{p}}^{*}=\hbar \omega_{\mathrm{p}} / \sqrt{\varepsilon_{\infty}}$, where $\varepsilon_{\infty}$ is the dielectric constant in the high frequency region. The plasmon energy is approximated to $\hbar \omega_{p}^{*} \approx 3 \mathrm{eV}$ for bulk $\mathrm{Au}$ and $\hbar \omega_{\mathrm{p}}^{*} \approx 4.7 \mathrm{eV}$ for bulk $\mathrm{Ag}[4,5]$. These energies are shown as solid circles in Fig. 1.

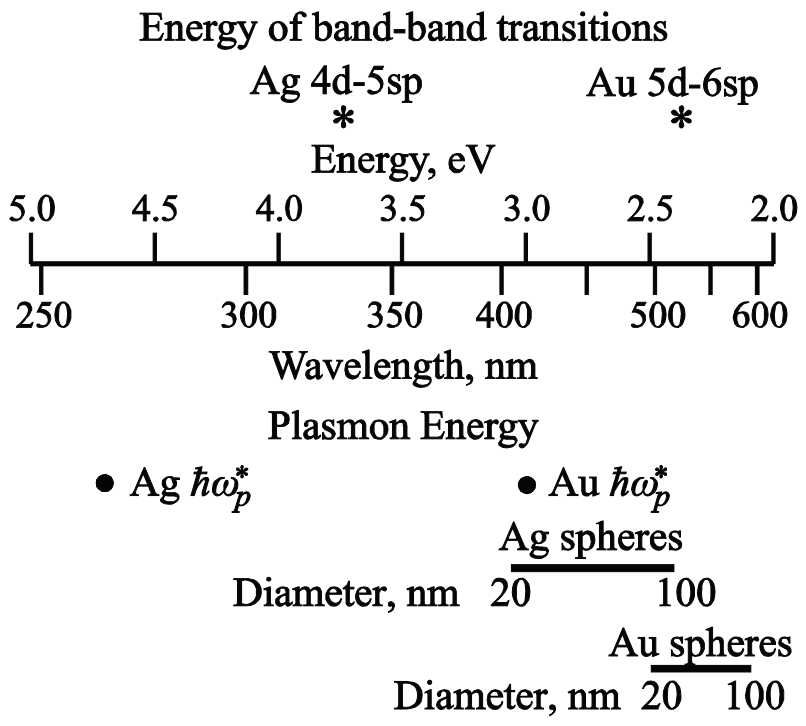

Fig. 1. The plasmon resonance $\hbar \omega_{p}^{*}$ of bulk Ag and Au (solid circles) and the ranges of surface plasmonic resonance for their nanoparticle spheres (solid bars). The asterisks indicate the interband transitions.

The localized surface plasmon resonance (determining the interaction between light and rough metal surfaces or metal nanoparticles) is dependent on the size and shape of the nanoparticle and also on the dielectric environment [6]. The solutions of the resonances for spheres are called Mie resonances. Hence, the surface plasmon energy for small spherical particles having a diameter of approximately $20 \mathrm{~nm}$ in the lowest dipole mode is equal to $\hbar \omega_{\mathrm{sp}}=\hbar \omega_{\mathrm{p}} / \sqrt{3}$ [3]. For spheres having a diameter in the range from 10 to $50 \mathrm{~nm}$, the surface plasmon resonance frequency and the linewidth is nearly independent of the particle size, although the resonance is highly sensitive to the shape of the particle [7]. The plasmon resonance of gold nanospheres of these diameters is at a wavelength of approximately $500 \mathrm{~nm}$. For silver spheres, the resonance is at approximately $400 \mathrm{~nm}$. As the size of the nanoparticles increases above $50 \mathrm{~nm}$, its unique plasmonic resonance shifts towards the red region of the visible spectrum. The linewidth of silver is narrower than the one for gold. The ranges of surface plasmonic resonance for silver and gold nanoparticles with a diameter of $20-100 \mathrm{~nm}$ are shown in Fig. 1 as solid bars [8-10]. The extinction coefficient for small metallic nanoparticles $(<25 \mathrm{~nm})$ is in most part dominated by absorption, while for larger particles it is dominated by scattering [11].

\section{Enhancement of photoluminescence in metals}

The quantum efficiency of the photoluminescence (PL) from bulk metals is very low, and typically in the order of $10^{-10}$ for noble metals $[4,12]$. This means that only one photon is emitted per each $10^{10}$ electron-hole pairs that are excited. The threshold energy of the interband transitions arises from the different nature of metals. For example, the interband threshold of the alkali metals is given by the excitations of the conduction-band electrons to higher bands only, since all the filled bands lie far below the conduction band. In this case the threshold energy is approximately equal to $E_{\text {th }}=0.64 E_{\mathrm{P}}$, where $E_{\mathrm{F}}$ is the Fermi energy [13]. In the case of noble metals, a direct excitation of conduction electrons to higher energy bands requires more energy than the threshold of direct excitation of $d$-band electrons into the conduction $s p$-band. The luminescence in the noble metals is attributed to the excitation of electrons into the sp-conduction band and subsequent direct radiative recombination. The resulting peak of the luminescence spectrum is centred around the interband absorption edge of the metal. For example, for silver the peak is centred at about $3.75 \mathrm{eV}$, for gold it is centred at $2.38 \mathrm{eV}$ [14]. These transition energies are presented as asterisks in Fig. 1.

The renewed interest in luminescence from metals arose with a number of discoveries related to noble metals with roughened surfaces or nanoparticles. The study of photoluminescence leads to 
the discovery of enhanced radiative recombination. Significant enhancements of the photoluminescence of up to $10^{4}-10^{8}$ times have been achieved for noble metallic nanoparticles [15-18]. There exist several models to explain this phenomenon. It was argued in the first model [19] that the light emission from the radiative recombination of $s p$-band electrons with $d$-band holes is enhanced by the local field associated with the nanoparticle plasmon oscillation. This would imply the possibility of an acceleration of the radiative processes. However, another model states [17] that the excited $d$-band holes recombine with $s p$-electrons nonradiatively and can excite plasmons of nanoparticles. These plasmons subsequently radiate, giving rise to the PL observed in the experiments. At present, however, the mechanism of PL enhancement in metal nanoparticles is still a question under debate.

\section{Surface enhanced Raman scattering}

One of the most important applications of metal nanostructures is surface enhanced Raman scattering (SERS). The SERS was discovered in 1974 and is based on the enhancement of Raman scattering of an analyte molecule near or on a roughened metal surface or metal nanoparticle [20,21]. It is currently a powerful analytical tool used in chemical and biochemical analysis and detection. The enhancement of the scattering arises mainly from two mechanisms: (i) electromagnetic (EM) field enhancement and (ii) chemical (Ch) enhancement. Assuming that the two contributions can be decoupled, the integrated photon flux in a SERS for one molecule experiment can be expressed as [22]

$$
\Phi_{\mathrm{SERS}}=\frac{I_{\mathrm{Inc}}}{\hbar \omega_{\mathrm{Inc}}} \sigma_{\mathrm{R}} M=\frac{I_{\mathrm{Inc}}}{\hbar \omega_{\mathrm{Inc}}} \sigma_{\mathrm{R}} M_{\mathrm{EM}} M_{\mathrm{Ch}} .
$$

Here $I_{\text {Inc }}$ and $\hbar \omega_{\text {Inc }}$ are the irradiance and photon energy of the incident field, $\sigma_{\mathrm{R}}$ is the cross section of the Raman scattering, and $M_{\mathrm{EM}}$ and $M_{\mathrm{Ch}}$ are the electromagnetic and chemical parts of the enhancement factor $M$, respectively. The highest enhancement up to $M \sim 10^{14}$ has been obtained with single molecules adsorbed on colloidal silver particles [23, 24]. However, a more typical SERS enhancement factor is presently in the range of $10^{8}-10^{10}$ [25].
The chemical enhancement, $M_{\mathrm{Ch}}$, contributes towards a smaller fraction of the full enhancement, $M$, and is in the range of $10^{1}-10^{3}[4,26]$. The origin of this effect is related to the formation of a new complex of the metal-adsorbed molecule. The excitation caused by the laser energy can either be in direct resonance with an electronic transition in the metal-molecule complex or it can profit from an indirect coupling (charge transfer) through the metal. The chemical enhancement is sensitive to the surface properties of the substrate and the nature of the adsorbed molecules, but the underlying mechanism is so far under discussion [21]. The electromagnetic enhancement, $M_{\mathrm{EM}}$, is the dominant parameter and is related to an increase in the electromagnetic field due to the excitations of localized surface plasmons. This effect leads to an enhancement of both the incoming and emitting light fields according to the electric field enhancement law of light $|\mathbf{E}|^{4}[4]$ :

$$
M_{\mathrm{EM}} \approx L_{\mathrm{EM}}\left(\omega_{0}\right) L_{\mathrm{EM}}\left(\omega_{\mathrm{s}}\right) \approx\left|\frac{E_{\mathrm{Loc}}\left(\omega_{0}\right)}{E_{0}\left(\omega_{0}\right)}\right|^{4},
$$

where $L_{\mathrm{EM}}\left(\omega_{0}\right)=\left|E_{\mathrm{Loc}}\left(\omega_{0}\right) / E_{0}\left(\omega_{0}\right)\right|^{2}$, and $L_{\mathrm{EM}}\left(\omega_{\mathrm{s}}\right)=$ $\left|E_{\mathrm{Loc}}\left(\omega_{\mathrm{s}}\right) / E_{0}\left(\omega_{\mathrm{s}}\right)\right|^{2}$ are the electric field enhancement factors for incoming and emitted (scattered) light, respectively. $E_{\text {Loc }}\left(\omega_{0}\right)$ and $E_{\text {Loc }}\left(\omega_{s}\right)$ are the enhanced local electric fields at the incoming and scattered frequencies, whereas $E_{0}\left(\omega_{0}\right)$ and $E_{0}\left(\omega_{s}\right)$ are the incident electric fields. The approximation in Eq. (2) is made due to the fact that the Raman shift wavelength is very small compared to the incoming wavelength. The theoretical calculations show that the electromagnetic enhancement, $M_{\mathrm{EM}}$ ' can reach the order of $10^{10}-10^{11}[22,27]$.

The enhancement factor of a silver sphere, $L_{\mathrm{EM}}$, is about 200 . However, its value depends on the distance from the surface, and enhancement is lower at higher distance [27]. Although spheres may not be the best practical enhancers, they are a good academic instrument used to illustrate the fundamentals of the plasmonic enhancement phenomena. In contrast, the highest enhancement is recorded from roughened silver surfaces. Thus, metal nanoparticles of various forms and arrays are used in SERS experiments. Metallic tips [28-30] and nanoholes [31] are also useful tools targeting enhancement investigations. 
In the view of quantum mechanics, the transition rate can be calculated using Fermi's golden rule

$$
\Gamma_{i j}=\frac{2 \pi}{\hbar}\left|V_{i j}\right|^{2} \rho(\hbar \omega),
$$

where $V_{i j}$ is a matrix element, and $\rho(\hbar \omega)$ denotes the density of the final states. As a dipole approximation, the transition rate can be replaced as $\Gamma_{i j} \rightarrow L_{\mathrm{EM}}\left(\omega_{0}\right) \Gamma_{i j}$, if the metal does not change the quantum state of the fluorophores. Please mark that this replacement is not valid for semiconductor confined systems such as quantum wells.

One important parameter is the distance dependence of SERS $[32,33]$. The spectrum is at its most enhanced when the particle is in direct contact with the metal surface. The field enhancement around a small metal sphere decays with $r^{-3}$, and using the $E^{4}$ approximation, the overall distance dependence should scale with $r^{-12}$. Taking into account the increased surface area that scales with $r^{2}$, the distance dependence of the field interacting with molecular or atomic shells should scale with $r^{-10}$ according to the law $I_{\text {SERS }} \propto\left[1+\frac{r}{a}\right]^{-10}$, where $I_{\text {SERS }}$ is the intensity of the Raman mode, $a$ is the average size of the field-enhancing features on the surface ( $a$ is of the order of $10 \mathrm{~nm}$ ), and $r$ is the distance from the surface to the adsorbate.

\section{Metal enhanced fluorescence}

Metallic surfaces can have unusual effects on nearby fluorophores and enhance the fluorescent emission [11]. This effect is called metal-enhanced fluorescence (MEF) or surface plasmon-enhanced fluorescence (SPEF). The nature of influence depends on the distance $r$ from the metal to the fluorophore [34, 35]; however, dependence is different in comparison with SERS case. At distances that are slightly greater than the emission wavelength $(r \geq 100 \mathrm{~nm})$ the emission is caused primarily by photons and the fluorescent lifetime exhibits an oscillatory behaviour as a function of the distance. The oscillations arise from interference between the directly radiated emission and that being reflected from the metal. At distances in the order of 5-50 nm (larger than the atomic dimensions but somewhat less than the wavelength) the fluorescing molecule is strongly coupled to the propagating surface plasmons on the metal. At very small values of $r \leq 1 \mathrm{~nm}$, the non-radiative processes dominate in the decay rate. Thus, for observation of the enhanced fluorescence, a nanometre-thin dielectric spacer layer is often required to prohibit the non-radiative excitation transfer from the molecule to the metal.

The power radiated as fluorescence photons is proportional to the absorbed power $P_{\text {Fluo }}=P_{\text {Abs }} Q$, where $Q$ is the fluorescence quantum yield (the ratio of the number of photons emitted to the number absorbed). It characterizes the competition between the radiative and non-radiative decays, and is given by $Q=\Gamma_{\mathrm{Rad}} /\left(\Gamma_{\mathrm{Rad}}+\Gamma_{\mathrm{NR}}\right)$, where $\Gamma_{\mathrm{Rad}}$ means radiative and $\Gamma_{\mathrm{NR}}$ means non-radiative decay rates [21].

Metal surface-enhanced fluorescence arises from the strong electromagnetic coupling attained between a molecule adsorbed at or near a metal surface and the metal surface as a result of excited localized surface plasmon resonances. The changes in fluorescence, as in the case of SERS enhancement, can be understood within classical EM theory. In our simple considerations we have assumed that the electronic energy levels are not affected by the adsorption. Thus, the fluorescence enhancement factor can be expressed as [36]

$$
M_{\text {Fluo }}\left(\omega_{\mathrm{s}}\right)=\frac{P_{\text {Fluo }}}{P_{\text {Fluo }}^{0}}=\frac{P_{\text {Abs }}}{P_{\text {Abs }}^{0}} \frac{Q}{Q^{0}},
$$

where the superscript zero refers to radiation without enhancement. Since the electric field of light may change in the vicinity of the metallic surface absorption, as discussed previously in SERS case, the local field can be modified by the enhancement factor $L_{\mathrm{Loc}}\left(\omega_{0}\right)=L_{\mathrm{EM}}\left(\omega_{0}\right)=\left|E_{\mathrm{Loc}}\left(\omega_{0}\right) / E_{0}\left(\omega_{0}\right)\right|^{2}$. Consequently, the absorbed power, excitation rate, or the absorption cross section is modified by the same factor. Different definitions are used in the analysis of the metal enhancement of fluorescence, but these are interdependent and relate principally to the same physical phenomenon. The single frequency approximation is often used to simplify the analysis, since it assumes that the excitation and emission frequencies are the same, $\omega_{0}=\omega_{\mathrm{s}}$, due to the molecules being excited at or near the peak of their emission spectrum. 
The fluorescence enhancement factor depends on both the incident and radiated light as well as on the enhancement of the decay rate of the excited molecules [36-38]:

$$
M_{\text {Fluo }}\left(\omega_{\mathrm{s}}\right)=L_{\mathrm{Loc}}\left(\omega_{0}\right) \frac{L_{\mathrm{Rad}}\left(\omega_{\mathrm{s}}\right)}{L_{\text {Tot }}} \approx L_{\mathrm{Loc}}\left(\omega_{0}\right)=\left|\frac{E_{\mathrm{Loc}}\left(\omega_{0}\right)}{E_{0}\left(\omega_{0}\right)}\right|^{2}
$$

Here, $\omega_{0}$ is the laser excitation frequency, and $\omega_{\mathrm{s}}$ is the Stokes shifted fluorescence frequency. $L_{\text {Tot }}$ is the sum of radiative and non-radiative enhancement factors $L_{\mathrm{Tot}}=L_{\mathrm{Rad}}+L_{\mathrm{NR}}$, where $L_{\mathrm{Rad}}=\Gamma_{\mathrm{Rad}}+\Gamma_{\mathrm{Rad}}^{0}$. For moderate to large distances $L_{\mathrm{Rad}}$ and $L_{\text {Tot }}$ are approximately equal, and we estimate the maximum enhancement to be proportional to the $|\mathbf{E}|^{2}$ law. In contrast, when a molecule gets very close to a metal surface, $L_{\mathrm{Tot}}$ can be much larger than $L_{\mathrm{Rad}}$, resulting in the MEF enhancement approaching zero [35]. Although we have used the $L_{\text {Rad }}$ factor to describe the emission enhancement in the discussion, there exists another consideration which describes the enhanced emission as a sum $\left(\Gamma_{\mathrm{Rad}}+\Gamma_{\mathrm{m}}\right)$, where $\Gamma_{\mathrm{m}}$ is the rate emission part in the presence of a metallic surface $[39,40]$.

The challenge is to find a metal nanostructure and a molecule whose interaction can be maximized. For various molecules interacting with silver and gold nanostructures the achieved fluorescence enhancement factor have been reported to reach 400 times [4].

\section{Metal-semiconductor composite enhanced emission}

Native semiconductors and metals (e. g. noble) are optically active and are able to absorb radiation in the $1-3 \mathrm{eV}$ energy region. Hence, their composites can have interesting and varied optical properties depending on the nature of the components, their relative energy levels and their interactions. Noble metal-semiconductor system or composite nanocrystal system can lead to an enhancement or a quenching of either the absorption or the emission of light [42-47]. This effect may be exploited in practical applications, such as an enhancement of the quantum efficiency of light-emitting diodes [48, 49], the rise of efficiency in photovoltaic (solar cell) devices [43, 44, 50-52], as well as new applications such as nanoscale quantum generator SPASER (surface plasmon amplification by stimulated emission of radiation) [53-55].

The photoluminescence from semiconductors or semiconductor nanostructures can be enhanced or quenched by metal nanoparticles placed at an appropriate distance. For example, the enhancement of luminescence of $\mathrm{CdSe} / \mathrm{ZnSe}$ core-shell quantum dots on gold colloids has been studied as a function of distance between the metal and the semiconductor in the structure [56]. The maximum enhancement by a factor of 5 was achieved at a distance of about $11 \mathrm{~nm}$. A similar distance between the metal and the semiconductor is in many cases used to investigate PL enhancement.

There is a limited number of works that reports on the enhancement of the emission in metalsemiconductor systems. When one component is substantially dominant in size over the other, the optical properties of the composite tend to be primarily determined by the predominant component [57]. It was observed that the photoluminescence of semiconductor nanostructures such as quantum wells, quantum dots coated with noble metal films or nanoparticles can be enhanced by more than ten times [58]. However, the PL enhancement or quenching mechanism is more complex and is at present not fully understood. It is believed that if the surface plasmon energy of a metal is matched with the emitted photon energy of the surrounding semiconductor materials, the resulting resonance can lead to an energy transfer from the metal surface to the surroundings or vice versa [59]. The enhanced emission can come from the electric field that is amplified by plasmon resonance, which initiates the electromagnetic field enhancement factor that is proportional to $|\mathbf{E}|^{2}$, where $\mathbf{E}$ is local electric field initiated by the photons [47].

By combining together a metal and semiconductor nanostructure, electrons will transfer from the metal to the semiconductor, for example, from $\mathrm{Au}$ to the CdS shell [59]. This will lead to an electron accumulation around the interface of the CdS and $\mathrm{Au}$, which can initiate enhanced interactions between the electrons in the CdS shell and Au surface. However, we believe that an additional effect may occur. The accumulated electrons form a two dimensional electron gas like those found in selectively doped semiconductor structures. This gas may create a strong electric field that is capable of 
quenching potential recombinations that occur at the interface. The recombination is thus shifted to the flat band region where an enhancement of the emission can be realized [60]. This shows that the physics governing the emission enhancement in metal-semiconductor nanostructures is an inherent complicated phenomenon.

\section{Enhanced emission in semiconductor confined nanostructures}

The energy levels and density of states are dependent on the size of the semiconductor nanoscale structures such as quantum wells (2D), wires (1D) or dots (0D) [57]. The energy level spacing and exciton binding energy increases with decreasing dimensions [61]. This quantum confinement effect leads to a blue shift of the absorption onset of nanocrystals with decreasing size. In quantum well crystals that are of cubic symmetry, the valence band splits into the heavy and light hole bands that results in two kinds of optical transitions called heavy and light hole transitions, respectively [62]. One of the dominant features of the optical properties of nanoscale materials is the strong influence of excitonic transitions on the absorption and luminescence spectra. The optical properties are related to the oscillator strength which is determined by the square of the electric transition dipole moment.

The relationship between the absorption coefficient / oscillator strength and the excitonic lifetime on the size of the semiconductor nanoparticles is a tool used to investigate the physical properties of nanoparticles. It is also important for practical applications in order to enhance the oscillator strength of excitonic transitions [63]. This oscillator strength increases with decreasing semiconductor particle size $[61,64,65]$. The integrated emission measured from our GaAs/AlAs multiple quantum wells (MQWs) were 20 times higher compared to the bulk GaAs (Fig. 2). Since the MQWs structure and the GaAs layer are of approximately equal thickness, one may conclude that the difference in PL intensities is related to the enhanced emission from the MQW s structure. The spectrum from the MQWs is shifted toward higher energies compared to that of GaAs. This is related to the increasing oscillator strength in MQWs. However, the first principles of quantum

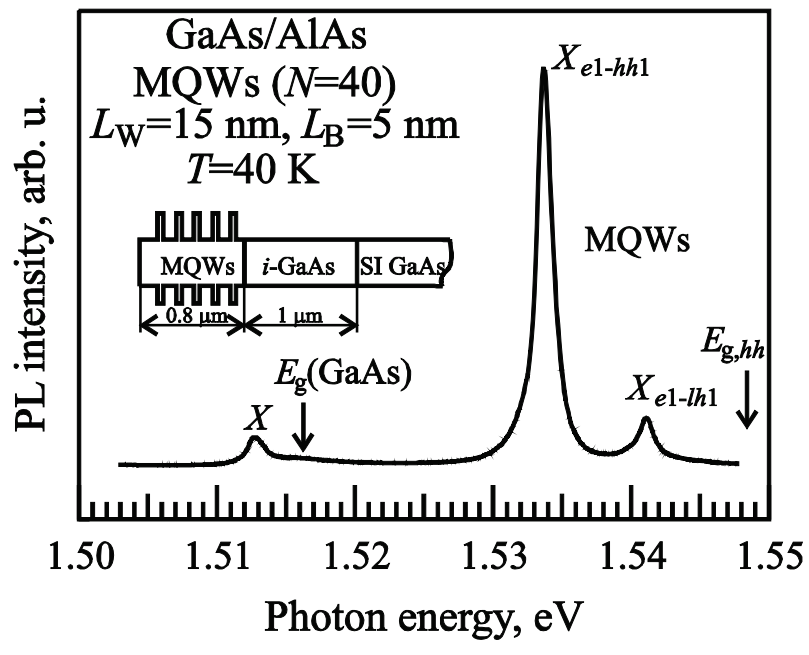

Fig. 2. The comparison of the PL spectrum from the GaAs/AlAs MQWs with the spectrum from a GaAs layer. The symbol $X$ indicates excitonic transition in the GaAs layer and the symbols $X_{e 1-h h 1}$ and $X_{e 1-l h 1}$ indicate heavyhole and light-hole excitonic transitions in MQWs.

mechanics need to be considered if a full analysis of the emission enhancement of confined semiconductor systems is to be performed.

To enhance the quantum effects and to achieve a strong coupling between light and matter, the semiconductor nanoparticles are placed inside microcavities [66-68]. The resulting interaction leads to the formation of exciton-polaritons: half-light, half-matter quasiparticles. This can induce a splitting between the new polariton modes, known as Rabi splitting [66, 67, 69]. Further investigations are also seeking to explore the newly observed effect of exciton-polariton lasing without inversion and Bose-Einstein condensation.

\section{The enhancement of PL in semiconductor homo- and heterojunctions}

Our examination of the photoluminescence spectra of $n^{+} / i$-GaAs homojunctions revealed an enhanced exciton emission of the homojunction in comparison with that of the $i$-GaAs active layer of the same structure $[70,71]$.

The PL spectrum of the $n^{+} / i$-GaAs homojunction with a $\mathrm{Si}$ doped $\left(10^{18} \mathrm{~cm}^{-3}\right)$ cap $n^{+}$layer of $100 \mathrm{~nm}$ film thickness, and the PL spectrum of the $i$-GaAs active layer, is shown in Fig. 3. Both spectra 


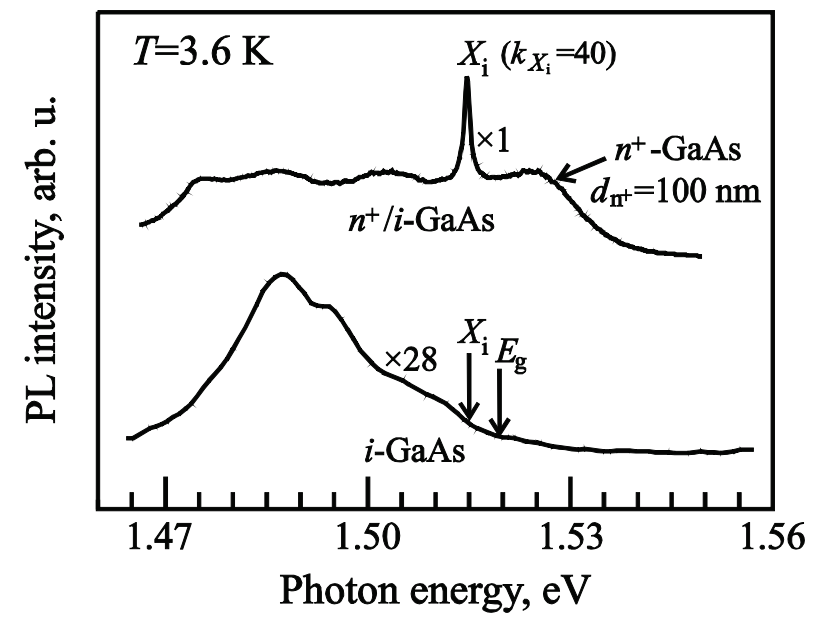

Fig. 3. The PL spectra (upper curve) of an $n^{+} / i$-GaAs homojunction and (bottom curve) of the $i$-GaAs active layer of the same structure at a temperature of $T=3.6 \mathrm{~K}$. The bottom curve enlarged 28 times.

were measured at a temperature of $T=3.6 \mathrm{~K}$. The estimated full width at half maximum (FWHM) of the exciton peak for the $n^{+} / i$-GaAs homojunction was about a few meV, whereas the FWHM for the epitaxial $i$-GaAs layer was about two times wider. The excitonic line of the homojunction is about 40 times more intense than the one of the active layer of the same structure. Two phenomena were observed: (i) the amplification and (ii) the narrowing of the excitonic line in the $n^{+} / i$-GaAs homojunction. Similar effects were observed in $\mathrm{Si} \delta$-doped GaAs structures [72], in the selectively Si-doped GaAs/AlGaAs heterostructures [60] and also in the AlInN/GaN heterostructures [73]. A high electric field forms at the interfaces from the active layer side in all these structures. In selectively doped heterostructures this field initiates a $2 \mathrm{D}$ electron gas. To clarify the observed energy band diagram, both the electron concentration and the electric field strength were calculated for our investigated structures. The results for the $n^{+} / i-G a A s$ homojunction structure are shown in Fig. 4.

This result shows that a correlation between the calculated built-in electric field strength and the measured enhancement of excitonic line intensity at various thicknesses of the $n^{+}$-GaAs cap layer (inset of Fig. 4) exists. The thickness variation of the $n^{+}$-GaAs layer does also control the carrier density, since the component that is captured at the sur- face will change the built-in electric field strength in the active layer of the homojunction. Thus, we can conclude that the built-in electric field and the enhancement of the excitonic emission are related phenomena. The enhancement was reported to span up to 3 orders of magnitude in the selectively doped $\mathrm{GaAs} / \mathrm{Al}_{x} \mathrm{Ga}_{1-x}$ As heterojunction structures [60].

The enhancement of PL in GaAs homojunctions and heterojunctions is a complex process that requires further investigations. The enhanced PL lines in all the investigated structures did not change energetic position in the spectrum, and the presence of a heavily doped layer caused the formation of a built-in high electric field near the interface. As was discussed previously, the free carriers can induce a plasmon of frequency $\omega_{\mathrm{p}}=\sqrt{n e^{2} /\left(\varepsilon_{\infty} \varepsilon_{0} m_{\mathrm{e}}{ }^{*}\right)}$. The calculated frequency, $\omega_{\mathrm{p}}$, ranged from $6.6 \cdot 10^{13}$ to

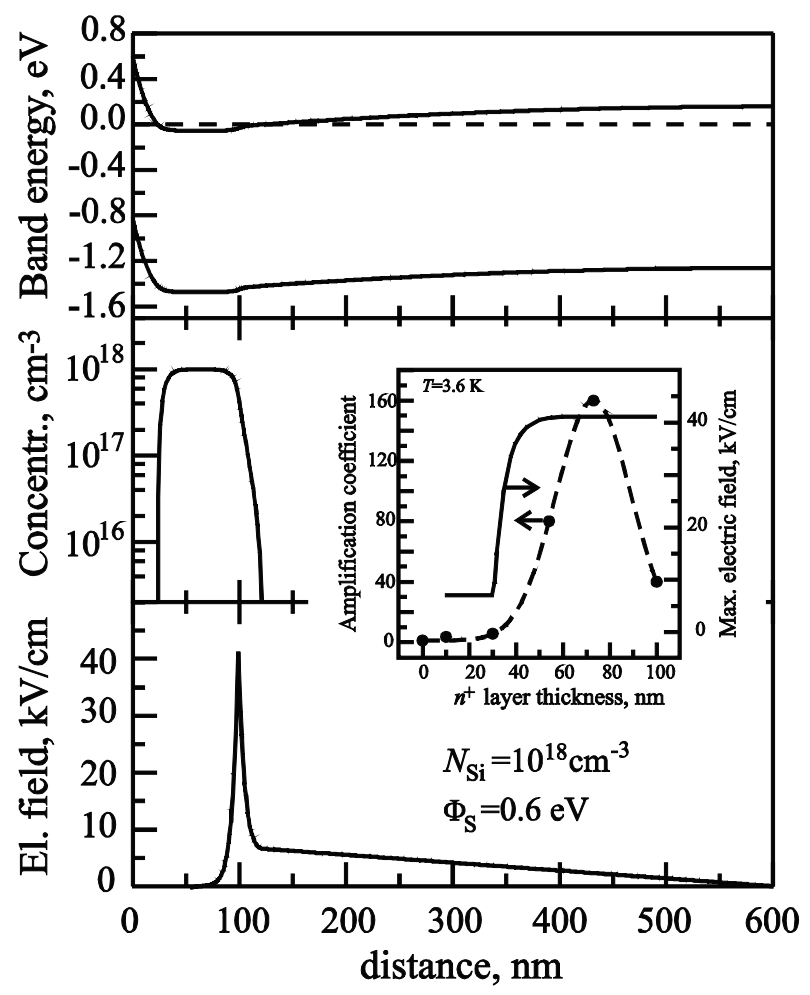

Fig. 4. Numerical calculations of the energy band diagram (top), electron concentration (middle) and the built-in electric field (bottom) of the $n^{+} / i$-GaAs homojunction $\left(N_{\mathrm{Si}}=10^{18} \mathrm{~cm}^{-3}\right)$ with a surface potential of $\Phi_{\mathrm{S}}=0.6 \mathrm{eV}$. The thickness of the cap $n^{+}$-GaAs layer is $100 \mathrm{~nm}$. A correlation between the enhanced exciton photoluminescence intensity and the calculated built-in electric field strength is shown in the inset. 
$1.1 \cdot 10^{14} \mathrm{~s}^{-1}$ taking into account the parameters $m^{*}=0.0665 m_{0}$ and $\varepsilon_{\infty}=10.92$. This considered, free carrier concentration was in the doping region from $1 \cdot 10^{18}$ to $3 \cdot 10^{18} \mathrm{~cm}^{-3}$, which meant that the plasmon energy ranged from 0.043 to $0.075 \mathrm{eV}$. This energy is too low and too far away from the resonant excitonic transition energy of $E_{X}=1.514 \mathrm{eV}$ in the GaAs (see Fig. 3).

The incident laser beam excites electrons to a certain depth of light penetration. These photoexcited carriers can form excitons in the $i$-GaAs layer, which in turn may recombine back to emitting photons. However, the presence of a strong builtin electric field prevents exciton formation in the close proximity to the $n^{+} / i$ interface region: holes are driven away from the interface while the photoexcited electrons drift towards the interface. Consequently, an electric field above $1 \mathrm{kV} / \mathrm{cm}$ has been shown to destroy excitons by tunneling. An accumulation of free carriers increases the number of excitons in the flat band region of $i$-GaAs layer. This can lead to a change in the emission rate, a change of quantum yield, and in part explain the observed enhancement of the excitonic line intensity in the $n^{+} / i$-GaAs homojunctions or heterojunctions. It is known that the highest metal enhancement of emission is achieved with a low efficiency emission of molecules. However, in our case the highest enhancement of PL was observed in the structures with the highest quality of active GaAs layer in $\mathrm{GaAs} / \mathrm{Al}_{x} \mathrm{Ga}_{1-x}$ As heterojuctions [60].

The origin of the line narrowing phenomenon is also not completely clear. Excited electrons and holes in epitaxial layers stay mostly near residual donors, acceptors or other inhomogenities that are randomly distributed in space. This interaction causes inhomogeneous broadening of the excitonic linewidth. The FWHM of the $X_{\mathrm{i}}$ line (see Fig. 3 ) at low temperatures in the $n^{+} / i-G a A s$ structure is similar to the linewidth of a high quality GaAs crystal. This fact suggests that the interaction of excitons with crystal imperfections is changed in the $n^{+} / i$-GaAs homojunction. However, the excitonic line narrowing also shows that the system possesses a macroscopic coherence. Such spontaneous appearance of coherence suggests that the exciton system in the structure has the potential of macroscopic occupation of a narrow mode spectrum. This phenomenon may also be related to a collective interaction of excitons in the homojunction or heterojuction structures.

\section{Summary of potential applications}

The enhancement of light emission in various nanostructures has been analysed. These enhancements are important in biological imaging and medical diagnostics applications. The enhancement of excitonic PL in GaAs homojunctions, $\delta$-doped GaAs structures, GaAs/AlGaAs selectively doped and AlInN/GaN heterostuctures has been experimentally obtained. This enhancement was shown to reach up to 3 orders of magnitude in GaAs/ AlGaAs selectively doped heterostuctures. These results can be applied to enhance the emission of light-emitting diodes, as well as increase the efficiency of solar cells.

\section{References}

[1] C.F. Bohren and D.R. Huffman, Absorption and Scattering of Light by Small Particles (Wiley, New York, 1998).

[2] W. Caseri, Nanocomposites of polymers and metals or semiconductors: Historical background and optical properties, Macromol. Rapid Commun. 21, 705-722 (2000).

[3] U. Kreibig and M. Vollmer, Optical Properties of Metal Clusters (Springer-Verlag, Berlin, 1995).

[4] S.A. Maier, Plasmonics: Fundamentals and Applications (Springer Science + Business Media LLC, New York, 2007).

[5] C. Sönnichsen, Plasmons in Metal Nanostructures, Dissertation (Ludwig-Maximilians-Universität München, München, 2001).

[6] K.L. Kelly, E. Coronado, L.L. Zhao, and G.C. Schatz, The optical properties of metal nanoparticles: The influence of size, shape, and dielectric environment, J. Phys. Chem. B 107, 668-677 (2003).

[7] M. Pelton, J. Aizpurua, and G. Bryant, Metalnanoparticle plasmonics, Laser Photon. Rev. 2(3), 136-159 (2008).

[8] http://www.nanocomposix.com. Retrieved 3 April 2011.

[9] http://www.nanopartz.com. Retrieved 3 April 2011.

[10]J.M. Steele, N.K. Grady, P. Nordlander, and N.J. Halas, in: Surface Plasmon Nanophotonics, eds. M.L. Brongersma and P.G. Kik (Springer, Dordrecht, 2007) pp. 183-196.

[11]K. Aslan and C.D. Geddes, in: Metal-Enhanced Fluorescence, ed. C.D. Geddes (Wiley, New Jersey, 2010) pp. 1-23.

[12] A. Mooradian, Photoluminescence of metals, Phys. Rev. Lett. 22(5), 185-187 (1969).

[13] N.W.Ashcroft and N.D. Mermin, Solid State Physics (Harcourt College Publishers, Orlando, 1976). 
[14]P. Apell, R. Monreal, and S. Lundqvist, Photoluminescence of noble metals, Phys. Scripta 38, 174-179 (1988).

[15]J.P. Wilcoxon, J.E. Martin, F. Parsapour, B. Wiedenman, and D.F. Kelley, Photoluminescence from nanosize gold clusters, J. Chem. Phys. 108(21), 9137-9143 (1998).

[16] M.B. Mohamed, V. Volkov, S. Link, and M.A. ElSayed, The 'lightning' gold nanorods: fluorescence enhancement of over a million compared to the gold metal, Chem. Phys. Lett. 317, 517-523 (2000).

[17]E. Dulkeith, T.Niedereichholz, T.A. Klar, J.Feldmann, G.von Plessen, D.I. Gittins, K.S. Mayya, and F.Caruso, Plasmon emission in photoexcited gold nanoparticles, Phys. Rev. B 70(20), 205424-4 (2004).

[18] O.A. Yeshchenko, I.M. Dmitruk, A.A. Alexeenko, M.Yu. Losytskyy, A.V. Kotko, and A.O. Pinchuk, Size-dependent surface-plasmon-enhanced photoluminescence from silver nanoparticles embedded in silica, Phys. Rev. B 79(23), 235438-8 (2009).

[19] G.T. Boyd, Z.H. Yu, and Y.R. Shen, Photoinduced luminescence from the noble metals and its enhancement on roughened surfaces, Phys. Rev. B 33(12), 7923-7936 (1986).

[20]M. Moskovits, in: Surface-Enhanced Raman Scattering: Physics and Applications, eds. K. Kneipp, M. Moskovits, and H. Kneipp (Springer-Verlag, Berlin, 2006) pp. 1-18.

[21]E. Le Ru and P. Etchegoin, Principles of Surface Enhanced Raman Spectroscopy and Related Plasmonic Effects (Elsevier, Amsterdam, 2009).

[22]H. Xu, J. Aizpurua, M. Käll, and P. Apell, Electromagnetic contributions to single-molecule sensitivity in surface-enhanced Raman scattering, Phys. Rev. E 62(3), 4318-4324 (2000).

[23] K. Kneipp, Y. Wang, H. Kneipp, L.T. Perelman, I. Itzkan, R.R. Dasari, and M.S. Feld, Single molecule detection using surface-enhanced Raman scattering (SERS), Phys. Rev. Lett. 78(9), 1667-1670 (1997).

[24] K. Kneipp, H. Kneipp, and H.G. Bohr, in: Surface-Enhanced Raman Scattering: Physics and Applications, eds. K. Kneipp, M. Moskovits, and H. Kneipp (Springer-Verlag, Berlin, 2006) pp. 261278.

[25]W.W. Parson, Modern Optical Spectroscopy: With Examples from Biophysics and Biochemistry (Springer-Verlag, Berlin, 2007).

[26]N. Valley, L. Jensen, J. Autschbach, and G.C. Schatz, Theoretical studies of surface enhanced hyper-Raman spectroscopy: The chemical enhancement mechanism, J. Chem. Phys. 133(5), 054103-8 (2010).

[27]E. Hao and G.C. Schatz, Electromagnetic fields around silver nanoparticles and dimers, J. Chem. Phys. 120(1), 357-366 (2004).

[28]B. Pettinger, in: Surface-Enhanced Raman Scattering: Physics and Applications, eds. K. Kneipp, M. Moskovits, and H. Kneipp (Springer-Verlag, Berlin, 2006) pp. 217-240.
[29]P. Verma, Y. Inouye, and S. Katawa, in: SurfaceEnhanced Raman Scattering:Physics and Applications, eds. K. Kneipp, M. Moskovits, and H. Kneipp (Springer-Verlag, Berlin, 2006) pp. 241-260.

[30] Tip Enhancement, eds. S. Kawata and V.M. Shalaev (Elsevier, Amsterdam, 2007).

[31] A.G. Brolo, E. Arctander, R. Gordon, B. Leathem, and K.L. Kavanagh, Nanohole-enhanced Raman scattering, Nano Lett. 4(10), 2015-2018 (2004).

[32] K.A. Willets and R.P. Van Duyne, Localized surface plasmon resonance spectroscopy and sensing, Annu. Rev. Phys. Chem. 58, 267-297 (2007).

[33] P.L. Stiles, J.A. Dieringer, N.C. Shah, and R.P. Van Duyne, Surface-enhanced Raman spectroscopy, Annu. Rev. Anal. Chem. 1, 601-626 (2008).

[34] G.W. Ford and W.H. Weber, Electromagnetic interactions of molecules with metal surfaces, Phys. Rep. 113(4), 195-287 (1984).

[35] P. Anger, P. Bharadwaj, and L. Novotny, Enhancement and quenching of single-molecule fluorescence, Phys. Rev. Lett. 96(11), 113002-4 (2006).

[36]E.C. Le Ru, J. Grand, N. Félidj, J. Aubard, G. Lévi, A.Hohenau,J.R.Krenn,E.Blackie, and P.G.Etchegoin, in: Metal-Enhanced Fluorescence, ed. C.D. Geddes (Wiley, New Jersey, 2010) pp. 25-65.

[37]E.C. Le Ru, P.G. Etchegoin, J. Grand, N. Félidj, J. Aubard, and G. Lévi, Mechanisms of spectral profile modification in surface-enhanced fluorescence, J. Phys. Chem. C 111, 16076-16079 (2007).

[38] P. Johansson, H. Xu, and M. Käll, Surface-enhanced Raman scattering and fluorescence near metal nanoparticles, Phys. Rev. B 72(3), 035427-17 (2005).

[39] C.D. Geddes and J.R. Lakowicz, Metal-enhanced fluorescence, J. Fluoresc. 12(2), 121-129 (2002).

[40]J.R. Lakowicz, Principles of Fluorescence Spectroscopy, 3rd ed. (Springer Science + Business Media, LLC, New York, 2006).

[41] D.J. Ross, N.P.W. Pieczonka, and R.F. Aroca, in: Metal-Enhanced Fluorescence, ed. C.D. Geddes (Wiley, New Jersey, 2010) pp. 67-90.

[42] D.M. Schaadt, B. Feng, and E.T. Yu, Enhanced semiconductor optical absorption via surface plasmon excitation in metal nanoparticles, Appl. Phys. Lett. 86(6), 063106-3 (2005).

[43] K. Nakayama, K. Tanabe, and H.A. Atwater, Plasmonic nanoparticle enhanced light absorption in GaAs solar cells, Appl. Phys. Lett. 93(12), 121904-3 (2008).

[44] Q. Gu, Plasmonic metallic nanostructures for efficient absorption enhancement in ultrathin CdTebased photovoltaic cells, J. Phys. D: Appl. Phys. 43, 465101-5 (2010).

[45] Y. Ito, K. Matsuda, and Y. Kanemitsu, Mechanism of photoluminescence enhancement in single semiconductor nanocrystals on metal surfaces, Phys. Rev. B 75 (3), 033309-4 (2007). 
[46]X. Zhou, Q. Wei, L. Wang, B. Joshi, Q. Wei, and K. Sun, Enhanced photoluminescence from gallium arsenide semiconductor coated with Au nanoparticles, Appl. Phys. A 96, 637-641 (2009).

[47] A.O. Govorov, G.W. Bryant, W. Zhang, T. Skeini, J. Lee, N.A. Kotov, J.M. Slocik, and R.R. Naik, Exciton-plasmon interaction and hybrid excitons in semiconductor-metal nanoparticle assemblies, Nano Lett. 6(5), 984-994 (2006).

[48]J. Vučković, M. Lončar, and A. Scherer, Surface plasmon enhanced light-emitting diode, IEEE J. Quantum Electron. 36(10), 1131-1144 (2000).

[49]S. Pillai, K.R. Catchpole, T. Trupke, G. Zhang, J. Zhao, and M.A. Green, Enhanced emission from Si-based light-emitting diodes using surface plasmons, Appl. Phys. Lett. 88(16), 161102-3 (2006).

[50] S. Pillai, K.R. Catchpole, T. Trupke, and M.A. Green, Surface plasmon enhanced silicon solar cells, J. Appl. Phys. 101(9), 093105-8 (2007).

[51] H.A. Atwater and A. Polman, Plasmonics for improved photovoltaic devices, Nat. Mater. 9, 205213 (2010).

[52] K.R. Catchpole and A. Polman, Plasmonic solar cells, Opt. Express 16(26), 21793-21780 (2008).

[53]D.J. Bergman and M.I. Stockman, Surface plasmon amplification by stimulated emission of radiation: quantum generation of coherent surface plasmons in nanosystems, Phys. Rev. Lett. 90(2), 027402-4 (2003).

[54] M.A. Noginov, G. Zhu, A.M. Belgrave, R. Bakker, V.M. Shalaev, E.E. Narimanov, S. Stout, E. Herz, T. Suteewong, and U. Wiesner, Demonstration of a spaser-based nanolaser, Nature 460(27), 11101113 (2009).

[55] M.I. Stockman, The spaser as a nanoscale quantum generator and ultrafast amplifier, J. Opt. 12(2), 024004-13 (2010).

[56]O. Kulakovich, N. Strekal, A. Yaroshevich, S. Maskevich, S. Gaponenko, I. Nabiev, U. Woggon, and M.Artemyev, Enhanced luminescence of CdSe quantum dots on gold colloids, Nano Lett. 2(12), 1449-1452 (2002).

[57]J.Z. Zhang, Optical Properties and Spectroscopy of Nanomaterials (World Scientific, Singapore, 2009).

[58]K. Okamoto, in: Nanoscale Photonics and Optoelectronics, eds. Z.M. Wang and A. Neogi (Springer Science + Business Media, LLC, New York, 2010) pp. 27-46.

[59]H.Y.Lin, Y.F.Chen,J.G.Wu,D.I.Wang, and C.C.Chen, Carrier transfer induced photoluminescence change in metal-semiconductor core-shell nanostructures, Appl. Phys. Lett. 88(16), 161911-3 (2006).

[60] J.Kundrotas,A.Čerškus, V.Nargelienè,A.Sužiedèlis, S. Ašmontas, J. Gradauskas, A. Johannessen, E. Johannessen, and V. Umansky, Enhanced exciton photoluminescence in the selectively $\mathrm{Si}$-doped $\mathrm{GaAs} / \mathrm{Al}_{x} \mathrm{Ga}_{1-x}$ As heterostructures, J. Appl. Phys. 108(6), 063522-7 (2010).
[61] T. Vossmeyer, L. Katsikas, M. Giersig, I.G. Popovic, K. Diesner, A. Chemseddine, A. Eychmüller, and H. Weller, CdS nanoclusters: synthesis, characterization, size dependent oscillator strength, temperature shift of the excitonic transition energy, and reversible absorbance shift, J. Phys. Chem. 98, 7665-7673 (1994).

[62]J. Kundrotas, A. Čerškus, S. Ašmontas, G. Valušis, B. Sherliker, M.P. Halsall, M.J. Steer, E. Johannessen, and P. Harrison, Excitonic and impurity-related optical transitions in Be $\delta$-doped GaAs/AlAs multiple quantum wells: Fractional-dimensional space approach, Phys. Rev. B 72(23), 235322-11 (2005).

[63] B. Deveaud, F. Clérot, N. Roy, K. Satzke, B. Sermage, and D.S. Katzer, Enhanced radiative recombination of free excitons in GaAs quantum wells, Phys. Rev. Lett. 67(17), 2355-2358 (1991).

[64] L.C. Andreani and A. Pasquarello, Accurate theory of excitons in GaAs- $\mathrm{Ga}_{1-x} \mathrm{Al}_{x}$ As quantum wells, Phys. Rev. B 42(14), 8928-8938 (1990).

[65] V. Voliotis, R. Grousson, P. Lavallard, and R. Planel, Binding energies and oscillator strengths of excitons in thin $\mathrm{GaAs} / \mathrm{Ga}_{07} \mathrm{Al}_{03}$ As quantum wells, Phys. Rev. B 52(15), 10725-10728 (1995).

[66] A.V. Kavokin, J.J. Baumberg, G. Malpuech, and F.P. Laussy, Microcavities (Oxford University Press, Oxford, 2007).

[67] The Physics of Semiconductor Microcavities: From Fundamentals to Nanoscale Devices, ed. B. Deveaud (Wiley-VCH, Weinheim, 2007).

[68] R. Shimada, Ü. Özgür, and H.Morkoç, in: Nanoscale Photonics and Optoelectronics, eds. Z.M. Wang and A. Neogi (Springer Science + Business Media, LLC, New York, 2010) pp. 47-64.

[69] G. Khitrova, H.M. Gibbs, M. Kira, S.W. Koch, and A. Scherer, Vacuum Rabi splitting in semiconductors, Nature Phys. 2, 81-90 (2006).

[70]V. Kazlauskaitè, A. Sužiedèlis, A. Čerškus, J. Gradauskas, S. Ašmontas, and J. Kundrotas, Enhancement of excitonic photoluminescence in silicon-doped $n^{+} / i$-GaAs structures, Lith. J. Phys. 49(3), 285-290 (2009).

[71] A.Čerškus,V.Nargelienė,J.Kundrotas,A.Sužiedèlis, S. Ašmontas, J. Gradauskas, A. Johannessen, and E. Johannessen, Enhancement of the excitonic photoluminescence in $n^{+} / i$-GaAs by controlling the thickness and impurity concentration of the $n^{+}$ layer, Acta Phys. Pol. A 119(2), 154-157 (2011).

[72] V. Nargelienè, S. Ašmontas, A. Čerškus, J. Gradauskas, J. Kundrotas, and A. Sužiedèlis, Peculiarities of excitonic photoluminescence in $\mathrm{Si}$ $\delta$-doped GaAs structures, Acta Phys. Pol. A 119(2), 177-179 (2011).

[73]J. Kundrotas, A. Čerškus, J. Liberis, A. Matulionis, J.H. Leach, and A.H. Morkoç, Enhancement and narrowing of excitonic lines in AlInN/GaN heterostructures, Acta Phys. Pol. A 119(2), 173-176 (2011). 


\title{
ŠVIESOS EMISIJOS SUSTIPRĖJIMAS NANODARINIUOSE
}

\author{
J. Kundrotas a , A. Čerškus a , V. Nargelienè ${ }^{\text {a }}$, A. Sužiedèlis ${ }^{\text {a }}$, S. Ašmontas a ${ }^{\text {, J. Gradauskas }}{ }^{\text {a }}$, \\ A. Johannessen ${ }^{\text {b }}$ E. Johannessen ${ }^{\text {b }}$ \\ ${ }^{a}$ Fiziniu ir technologijos mokslu centro Puslaidininkiu fizikos institutas, Vilnius, Lietuva \\ ${ }^{\mathrm{b}}$ Vestfoldo universitetinis koledžas, Borre, Norvegija
}

\section{Santrauka}

Apžvelgiami šviesos sustiprèjimo reiškiniai ịvairiose kvantinèse nanometrinèse sistemose. Pirmiausia pristatomas plazminis fotoliuminescencijos (fluorescencijos) sustiprejjimas metaluose ir metalų nanodalelèse, molekulèse ir puslaidininkiniuose nanodariniuose. Taip pat aptariama paviršiaus sustiprinta Ramano sklaida. Toliau nagrinejjamas eksitoninès spinduliuotès sustiprejjimas apribotuose nanometriniuose dariniuo- se, tokiuose kaip kvantiniai šuliniai, kvantinès gijos, kvantiniai taškai bei mikrorezonatoriai. Galiausiai pateikiami eksitoninès spinduliuotès sustiprèjimo GaAs vienalytėse sandūrose, GaAs $\delta$-legiruotose dariniuose bei GaAs/AlGaAs selektyviai legiruotuose ivvairiatarpèse sandūrose eksperimentiniai tyrimo rezultatai. Padaryta išvada, kad pastarieji reiškiniai gali būti panaudoti šviestukų ir saulès elementų efektyvumui padidinti. 